\title{
PENGARUH LATIHAN FISIK AKUT TERHADAP KADAR GULA DARAH PADA MAHASISWA FAKULTAS KEDOKTERAN UNIVERSITAS SAM RATULANGI MANADO
}

\author{
${ }^{1}$ Willem R. Matindas \\ ${ }^{2}$ Siantan Supit \\ ${ }^{2}$ Joice N. A. Engka \\ ${ }^{1}$ Kandidat Skripsi Fakultas Kedokteran Universitas Sam Ratulangi Manado
${ }^{2}$ Bagian Fisiologi Fakultas Kedokteran Universitas Sam Ratulangi Manado
Email: rezha_ddrummer@yahoo.co.id
}

\begin{abstract}
Physical exercise can influence body metabolism. The Harvard test is a simple method used in determining physical fitness. This test is performed by stepping up and down on a bench for certain periods of times. This study aimed to compare the levels of blood glucose of medical students of Sam Ratulangi University aged 20-22 years before and after performing the Harvard test. This was a field experimental study with One Group Pre-Post Test Design. The respondents were 35 students consisting of 22 males and 13 females who met the inclusion criteria. They were instructed to perform the Harvard test for five minutes and then were examined for blood glucose levels. The data were analyzed by using a t-test. The results showed an increase of the mean blood glucose levels from $75.80 \mathrm{mg} / \mathrm{dL}$ (before acute physical exercise) to $77.71 \mathrm{mg} / \mathrm{dL}$ (after acute physical exercise), but it was not statistically significant $(P>0.05)$. Conclusion: The acute physical exercise (the Harvard test) had no effect on before or after-exercise blood sugar levels.
\end{abstract}

Keywords: acute physical exercise, Harvard test, blood sugar level

\begin{abstract}
Abstrak: Latihan fisik dapat mempengaruhi metabolisme tubuh. Harvard test merupakan latihan fisik berupa naik turun bangku yang dilakukan dalam kurun waktu tertentu. Penelitian ini bertujuan untuk membandingkan kadar gula darah sebelum dan sesudah diberikan latihan fisik akut (Harvard test) pada mahasiswa Fakultas Kedokteran Unsrat dengan kisaran usia 2022 tahun. Jenis penelitian ini bersifat eksperimental lapangan dengan rancangan One Group Pre-Post Test Design. Subyek penelitian sebanyak 35 mahasiswa, terdiri dari 22 laki-laki dan 13 perempuan yang memenuhi kriteria inklusi. Semua subyek diberikan latihan fisik akut (Harvard test) selama lima menit dan kemudian dilakukan pemeriksaan kadar gula darah. Data statistik di analisis mengunakan uji-t. Hasil penelitian memperlihatkan terjadinya peningkatan rerata kadar gula darah dari $75,80 \mathrm{mmHg}$ (sebelum latihan fisik akut) menjadi $77,71 \mathrm{mmHg}$ (sesudah latihan fisik akut) yang secara statistik tidak bermakna $(P>0,05)$. Simpulan: Latihan fisik akut (Harvard test) tidak memengaruhi kadar gula darah sebelum dan sesudah latihan.
\end{abstract}

Kata kunci: latihan fisik akut, Harvard test, kadar gula darah.

Olahraga merupakan aktivitas yang dilakukan seseorang untuk meningkatkan dan memelihara kebugaran tubuh. Pengaruh aktivitas fisik terhadap tubuh dapat bersifat positif yaitu memperbaiki daya tahan dan kebugaran tubuh, maupun bersifat negatif yaitu menghambat berbagai hal yang fisiologik atau merusak kesehatan. Aktivitas fisik yang dilakukan secara teratur dengan intensitas ringan sampai sedang akan meningkatkan daya tahan dan kebugaran tubuh. Para ahli menganjurkan 
agar setiap individu melakukan aktivitas fisik secara teratur karena dapat mengurangi resiko berbagai macam penyakit, antara lain penyakit jantung, diabetes, dan obesitas. Aktivitas fisik dengan intensitas berat dan melelahkan dapat menyebabkan gangguan pada sistem kerja jantung. ${ }^{1}$

Latihan fisik terbagi menjadi dua jenis yaitu latihan aerobik dan latihan anaerobik. Secara harafiah aerobik berarti menggunakan udara dan mengacu pada penggunaan oksigen secara memadai untuk memenuhi kebutuhan energi selama latihan melalui metabolisme aerobik. Latihan anaerobik merupakan latihan tanpa menggunakan oksigen. ${ }^{2}$

Menurut American College of Sport Medicine (ACSM), latihan aerobik merupakan suatu kegiatan yang menggunakan kelompok otot-otot besar yang dapat dilakukan terus menerus dengan irama. ${ }^{3}$ Latihan fisik yang teratur akan meningkatkan kepekaan insulin sehingga makin sedikit terapi insulin dari luar tubuh yang dibutuhkan. Oleh karena itu, penyandang diabetes melitus sangat dianjurkan untuk melakukan latihan fisik secara teratur. ${ }^{3.4}$ Penelitian oleh Bell Christopher dari American Diabetes Association (ADA) menyatakan bahwa latihan fisik jangka pendek dapat memengaruhi metabolisme tubuh (dalam hal ini, karbohidrat), yaitu menaikkan kadar gula darah. ${ }^{4}$

\section{METODE PENELITIAN}

Jenis penelitian yang dilakukan ialah penelitian eksperimental lapangan dengan rancangan penelitian One group Pre-Post Test Design. Penelitian dilaksanakan pada November 2011 sampai dengan Januari 2012, dengan lokasi penelitian di Kampus Fakultas Kedokteran Unsrat Manado, dengan populasi penelitian yaitu mahasiswa Fakultas Kedokteran Unsrat.

Sebagai kriteria inklusi yaitu terdaftar sebagai mahasiswa Fakultas Kedokteran Unsrat Manado, berusia 18-26 tahun, bersedia menjadi responden dan menandatangani informed consent, serta sehat pada saat penelitian; sedangkan sebagai kriteria eksklusi yaitu atlit atau anggota klub fitness.

\section{Variabel penelitian}

Sebagai variabel bebas yaitu latihan fisik (Harvard test), sedangkan variabel tergantung yaitu kadar gula darah.

Dalam penelitian ini, latihan aerobik yang diberikan untuk menilai kebugaran fisik yaitu Harvard test yang sudah dimodifikasi agar sesuai dengan situasi dan kondisi pada saat dilaksanakan pengambilan data. Latihan naik-turun bangku Harvard selama \pm 5-6 menit dengan irama konstan dengan menggunakan metro-nome. ${ }^{5,6}$

Gula darah merupakan karbohidrat dalam makanan yang diserap dalam jumlah besar ke dalam darah dan merupakan bahan bakar utama bagi jaringan tubuh, yang akhirnya digunakan oleh sel tubuh untuk membentuk ATP. Kadar gula darah normal yang dipakai 70-110 mg/dL. Pada penelitian ini kadar gula darah diambil sesaat sebelum perlakuan dan segera sesudah perlakuan modifikasi Harvard test.

Data yang diperoleh dilakukan uji normalitas data, dan dilanjutkan dengan uji $\mathrm{t}$ berpasangan dengan derajat kepercayaan 95\% $(P<0,05)$.

\section{HASIL PENELITIAN DAN BAHASAN}

\section{Karakteristik subyek}

Pada penelitian ini diperoleh rerata berat badan $60,97 \pm 12,435 \mathrm{~kg}$ dan rerata tinggi badan $164,77 \pm 7,822 \mathrm{~cm}$, yang menyatakan bahwa subyek memliki karakteristik fisik dalam batas normal. Rerata indeks massa tubuh (IMT) 22,3123 \pm $3,44127 \mathrm{~kg} / \mathrm{m}^{2}$ yang menyatakan bahwa subyek dalam kategori status gizi baik. Patokan yang digunakan yaitu dari WHO yang menyatakan bagi pemakaian internasional IMT 18,5-24,9 dianggap normal; 25,0-29,9 berat berlebih (overweight); dan $\geq 30$ obesitas. Seseorang dengan status gizi yang baik atau IMT normal memiliki kemampuan fisik yang baik dibandingkan dengan seorang dengan status gizi kurang ataupun berlebihan. ${ }^{1}$ 


\section{Pengaruh latihan fisik akut Harvard test terhadap perubahan kadar gula darah}

Temuan utama dari penelitian ini yaitu latihan fisik akut dapat mempengaruhi kadar gula darah. Kadar gula darah sebelum melakukan Harvard test 75,7428 \pm $8,6273 \mathrm{mg} / \mathrm{dL}$ sedangkan yang sesudah melakukan Harvard test 77,7142 $\pm 10,4756$ $\mathrm{mg} / \mathrm{dL}$; hal ini menunjukkan terjadinya peningkatan kadar gula darah setelah melakukan latihan fisik akut (Harvard test).

Hasil penelitian ini sejalan dengan hasil penelitian Bell berjudul Short-term sprint-interval training and metabolic regulation in adult humans yang menyatakan bahwa latihan fisik jangka pendek dapat mempengaruhi metabolisme tubuh, yaitu metabolisme karbohidrat dimana dapat menaikkan kadar gula dalam darah. ${ }^{4}$ Menurut Fox dan Kilvert, latihan fisik juga dapat menurunkan kadar gula darah. Pengaruh latihan fisik akut terhadap tubuh dapat bertahan hingga setelah aktivitas selesai (otot-otot menyimpan ulang energi dengan cara mengubah glukosa yang berlebihan menjadi glikogen). Gula darah bisa turun dua jam atau lebih setelah latihan. $^{7}$

Kadar gula darah biasanya turun setelah melakukan olahraga asal saja tubuh memiliki persediaan insulin yang cukup untuk memfasilitasi penggunaan glukosa oleh sel-sel tubuh. Latihan fisik dapat mempengaruhi kadar glukosa darah sampai 48 jam. Bila kadar glukosa sudah rendah sebelum melakukan latihan fisik, tubuh akan menarik simpanan glukosa berupa glikogen dalam hati dan otot untuk menyediakan energi. Setelah 20-30 menit, simpanan energi ini akan sangat berkurang sehingga bila terlalu memaksakan diri, kadar gula darah akan segera naik. Setelah periode latihan yang terus-menerus dan pada tingkat yang tepat, kadar gula darah akan turun. ${ }^{11}$ Penyandang diabetes mungkin memiliki peningkatan atau penurunan kadar gula darah saat diberikan latihan fisik dengan jangka pendek (short term) seperti yang dikemukakan oleh Seibel John, dalam jurnal American Diabetes Association
(ADA) dengan judul "Type 2 Diabetes and Exercise". Insulin dilepaskan dari pankreas ketika jumlah glukosa dalam darah meningkat, misalnya setelah makan. Insulin merangsang hati dan otot untuk mengambil kelebihan glukosa. ${ }^{10} \mathrm{Hal}$ ini mengakibatkan penurunan kadar gula darah. Saat diberikan latihan fisik, tubuh membutuhkan energi ekstra atau bahan bakar (dalam bentuk glukosa) untuk melakukan aktivitas. Otot dan hati akan melepaskan glukosa ke dalam darah untuk menjaga agar kadar gula darah tetap stabil. Pada latihan jangka panjang (long term), otot-otot akan lebih membutuhkan banyak energi, dan tubuh akan menggunakan semua glukosa yang ada termasuk yang disimpan dalam hati dan otot-otot, yang akan menyebabkan penurunan kadar gula darah (Gambar 1).

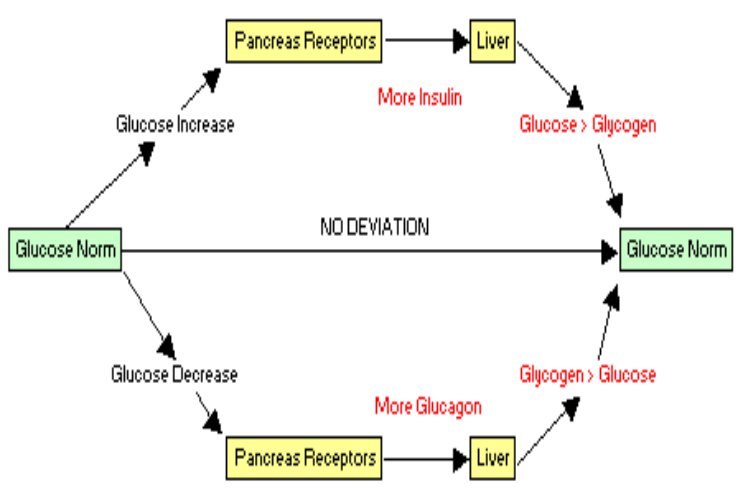

Gambar 1. Gambaran prinsip negative feedback control dalam hal kerja yang melibatkan kadar gula darah. ${ }^{12}$

Penelitian Myers 'Exercise and Cardiovascular Health' menyatakan bahwa latihan fisik memiliki efek yang menguntungkan pada banyak faktor risiko penyakit kardiovaskuler. Latihan fisik mendorong penurunan berat badan dan dapat membantu mengurangi tekanan darah. Selain itu, latihan fisik juga dapat mengurangi kadar gula dalam darah. ${ }^{9}$

Pengaruh kadar gula darah terhadap latihan fisik akut dengan Harvard test sebelum dan sesudah perlakuan pada penelitian ini menggunakan uji-t dan didapatkan hasil yang tidak bermakna dengan 
$P>0,05$. Hal ini mungkin disebabkan karena waktu yang diberikan untuk perlakuan berupa Harvard test berlangsung terlalu singkat, yaitu hanya lima menit.

\section{SIMPULAN}

Berdasarkan hasil penelitian dapat disimpulkan bahwa tidak terdapat pengaruh bermakna dari latihan fisik akut, dalam hal ini Havard test, terhadap kadar gula darah sebelum dan sesudah latihan walaupun terdapat peningkatan rerata kadar gula darah setelah latihan.

\section{SARAN}

Subyek yang diteliti sebaiknya diberikan pengarahan supaya aktivitas fisik dapat dilakukan dengan baik dan benar, sehingga latihan fisik akut dapat memberikan gambaran perubahan kadar gula darah yang maksimal. Selain itu, untuk penelitian selanjutnya dianjurkan dilakukan pada latihan jangka panjang/long term exercise.

\section{DAFTAR PUSTAKA}

1. World Health Organization (WHO). Pacific Physical Activity Guidelines for Adults [homepage on the Internet]. c2008 [cited 2012 Nov 02]. Available from: http://www.wpro.who.int/NR/rdonlyres /6BF5EE82-8509-4B2F-8388-CE9DB CCA0F8/0/PAG_layout2_22122008.pdf.

2. Aerobic Versus Anaerobic. Doctor Senior Exercise [homepage on the Internet]. Nodate [cited 2012 Nov 02]. Available from URL: http://doctors exercise. com/journal/aerobic.htm.

3. Len K, and Chantal AV. Energy Expenditure in Different Modes of Exercise Classification of Aerobic [homepage on the Internet]. Nodate [cited 2012 Nov 02]. Available from URL: http: //www.acsm.org/docs/current-comments/ energyexpendindifferentexmodes.pdf.

4. American Diabetes Association. Diabetes Basics [homepage on the Internet]. Nodate [cited 2012 Nov 02]. Available from URL: http://www.diabetes. org/diabetes-basics/type-2/.

5. Mackenzie B. Harvard Step Test [homepage on the Internet]. 2007 [cited 2012 Nov 02]. Available from: http://www.brian mac.co.uk/havard.htm.

6. Lister E. Pengaruh Latihan Aerobik Intensitas Ringan dan Sedang terhadap jumlah trombosit pada remaja putri di Universitas Prima Indonesia, [Tesis]. Medan: Universitas Sumatera Utara, 2008

7. Fox C, Kilvert A. Diabetes tipe 1. Jakarta: Niaga Swadaya, 2010.

8. D'Adamo PJ, Whitney C. Diabetes: Fight It with the Blood Type Diet. USA: Penguin; 2004.

9. Gibney MJ, Margetts BM. Public Health Nutrition. Oxford: Blackwell Publishing Ltd; 2005.

10. John A. Seibel, Type 2 Diabetes and Exercise, US Department of Health and Human Services [homepage on the internet]. 2009 [cited 2012 Nov 02]. Available from: http://diabetes.webmd. com/guide/exercise-guidelines.

11. The Department of Nutrition for Health and Development (NHD). WHO BMI classification [homepage on the internet]. Available from: http://apps. who.int/bmi/index.jsp?introPage=intro 3.html.

12. Sugar Homeostasis, Sugar Regulation. Biology Online [homepage on the internet]. Nodate [cited 2012 Nov 02]. Available from URL: http://www. biologyonline.org/4/3_blood_sugar.htm. 